\title{
D-Glyceric Acidemia: An Inborn Error Associated with Fructose Metabolism
}

\author{
M DURAN, F. A. BEEMER, L. BRUINVIS, D. KETTING, AND S. K. WADMAN \\ University Children's Hospital, "Het Wilhelmina Kinderziekenhuis" [M.D., F.A.B., L.B., D.K., S.K.W.] and \\ Clinical Genetics Center [F.A.B.], Utrecht, The Netherlands
}

\begin{abstract}
A mentally retarded girl with epileptic seizures is described. Urinary organic acid screening revealed a massive excretion of glyceric acid, a normally barely detectable metabolite. Hyperglycinemia was not observed. Capillary gas chromatography of the $O$-acetylated (-)menthyl ester of urinary glyceric acid showed the substance to have the D-configuration. The urinary D-glycerate excretion remained unaltered after an oral load with $200 \mathrm{mg} / \mathrm{kg}$ L-serine, but oral loading with fructose $(1 \mathrm{~g} / \mathrm{kg})$ or dihydroxyacetone $(1 \mathrm{~g} / \mathrm{kg})$ caused a sharp increase of the $\mathrm{D}$ glycerate excretion. Treatment with a diet moderately restricted in fructose led to some clinical improvement as judged by subjective criteria. The metabolic lesion is thought to be located at some step of the fructose catabolic pathway, possibly at the level of hepatic triokinase deficiency. (Pediatr Res 21: 502-506, 1987)
\end{abstract}

\section{Abbreviations}

GAPD, glyceraldehyde-3-phosphate dehydrogenase NKH, nonketotic hyperglycinemia TMS, trimethylsilyl

Hb, hemoglobin

D-Glyceric acidemia seems to be an extremely rare inborn error of metabolism. To date only three isolated cases have been reported (1-3). The clinical presentation of the patients varied: the patient described by Wadman et al. (2) had a chronic metabolic acidosis and only a moderate developmental delay, whereas the patients described by Brandt et al. (1) and Grandgeorge et al. (3) showed all characteristic symptoms of NKH such as extreme hypotonia, deep mental retardation, myoclonic jerks, and grand mal seizures. Brandt's patient not only had the clinical signs of $\mathrm{NKH}$, but actually had elevated levels of glycine in his plasma and urine. The concentration of D-glycerate in urine of the previously described patients ranged from 1-116 $\mathrm{mmol} / \mathrm{liter}$.

A clear-cut enzyme defect leading to D-glyceric acidemia has not yet been found, although K $\phi$ lvraa et al. (4) found evidence for a decreased activity of D-glycerate dehydrogenase in the fresh leukocytes of Brandt's patient. Enzyme studies were not performed in the other two patients.

Herein we describe a patient with D-glyceric acidemia. Results of biochemical investigations as well as of clinical studies, designed to obtain more insight in the metabolic defect, will be given.

Received June 2, 1986; accepted December 19, 1986

Correspondence Dr. M. Duran, University Children's Hospital, Het Wilhelmina Kinderziekenhuis, Nieuwe Gracht 137, 3512 LK Utrecht, The Netherlands.

\section{CASE REPORT}

The proband B., the first child of healthy, nonrelated parents, was born at home after an uneventful gestation of $38 \mathrm{wk}$; her birth weight was $2800 \mathrm{~g}$. There were signs of perinatal asphyxia: crying started late. Apgar scores were not recorded. The mother's next pregnancy ended with a spontaneous abortion at $11 \mathrm{wk}$; the third pregnancy resulted in the birth of a child with spina bifida who died in the neonatal period. Subsequently two healthy children were born.

In the first weeks of life the patient was noted to be hypotonic and she had severe feeding difficulties. Motor development was slow: she could only sit without support at the age of 18 months. At the age of 12 months she had her first seizure located at the right half of the body during a febrile period. Recurrent seizures were noticed during the following week. Thereafter a right-sided spastic hemiplegia was observed. Two kinds of seizures became manifest: adversive fits as well as focal seizures at the right part of the body. Psychomotor development appeared to be severely retarded.

At the age of $5 \frac{1}{2}$ yr she was referred for evaluation; the parents asked for genetic advice. On admission her body weight was on the 10th percentile, her length on the 50th percentile, and her skull circumference on the 75 th percentile. She was brachycephalic, had a telecanthus, a depressed nose bridge, and low implanted ears. Her dental gums were hypertrophic, whereas her arms and hands showed signs of automutilation. She also had attacks of aggressive behavior (i.e. biting and shouting) especially toward the parents. Neurologically there was still a right-sided hemiplegia. Her epilepsy was treated with diphantoin $225 \mathrm{mg}$, valproate $900 \mathrm{mg}$, and clonazepam $0.6 \mathrm{mg}$ daily.

Laboratory investigations. None of the routine clinical chemical determinations revealed abnormalities. Anemia was not observed. A broad screening for inborn errors of metabolism including the chromatographic analysis of amino acids, organic acids, purines and pyrimidines, mono-, di-, and oligosaccharides, acid mucopolysaccharides, phenolic acids, and imidazoles was carried out. This revealed an abnormal glyceric aciduria.

\section{MATERIALS AND METHODS}

Urinary organic acid screening was done by gas chromatography/mass spectrometry of the pertrimethylsilyl derivatives after extraction two times with two volumes ethyl acetate (5). Because of the poor extraction yield of of glyceric acid a quantitative determination was achieved by extracting the urine five times with four volumes of ethyl acetate, giving a reproducible recovery of $25 \%$. Plasma glycerate was analyzed in the same manner. The lower detection limit of this technique was established to be 10 $\mu \mathrm{mol} / \mathrm{liter}$. Oxoacids and aldehydes such as glyceraldehyde were analyzed in the form of methoximes or ethoximes by capillary gas chromatography: prior to ethyl acetate extraction the sample was left to react with $4 \mathrm{mg}$ methoxyamine $\mathrm{HCl}$ or ethoxyamine 
$\mathrm{HCl}$ for each $\mathrm{ml}$ of urine at room temperature for $2 \mathrm{~h}$. The absolute configuration of the urinary glyceric acid was established by capillary gas chromatographic separation of the $O$-acetylated $(-)$-menthyl esters, essentially as described previously (2). The ethyl acetate extract was not purified further prior to the derivatization. $D$ - and $\mathrm{L}$-glyceric acids to be used as reference compounds were synthesized according to Wohl and Schellenberg (6) (J. P. Kamerling, laboratory for Organic Chemistry, State University, Utrecht). The patient's erythrocyte contents of intermediates of the glycolytic pathway and the activities of various glycolytic enzymes were measured by previously established techniques (7).

Oral loading tests with L-serine $(200 \mathrm{mg} / \mathrm{kg})$, fructose $(1 \mathrm{~g} / \mathrm{kg})$, and dihydroxyacetone $(1 \mathrm{~g} / \mathrm{kg})$ were performed after an overnight fast; the fasting state was subsequently maintained for 4 more $h$. Urine samples were collected $24 \mathrm{~h}$ prior to loading and in two 6$\mathrm{h}$ portions and a $12-\mathrm{h}$ portion after loading when possible. Venous plasma samples were taken at regular intervals starting at the moment of loading. During the in vivo studies the antiepileptic medication was continued. Fructose in plasma was analyzed by a colorimetric method using thiobarbituric acid (8). It should be mentioned that additional in vivo studies were not allowed by the parents.

\section{RESULTS}

As part of the screening program for inherited metabolic disorders, urinary organic acids were analyzed. This showed, in addition to the multiple peaks due to valproate medication, a prominent peak in the position of glyceric acid. Its identity was confirmed by gas chromatography/mass spectrometry which showed the molecular mass to be 322 . Major fragments were observed at $\mathrm{m} / \mathrm{z}$ values of $307,292,205$, and 189 . As glyceric acid may occur in two forms, its absolute configuration was established after conversion of the substance present in the ethyl acetate extract into a diastereomer by reacting it with (-)menthol and acetic anhydride. Capillary gas chromatography of the acetylated (-)-menthyl esters showed the urinary glycerate to be exclusively in the D-form. Neither glyceraldehyde nor hydroxypyruvate could be detected in random urine samples by analyzing urinary oxo-compounds as their methoxime-TMS or ethoxime-TMS derivatives. Urinary D-glycerate levels in the present patient showed a considerable variation: values between 0.56 and $9.30 \mathrm{mmol} / \mathrm{liter}$ (or $0.57-17.06 \mathrm{mmol} / \mathrm{g}$ creatinine) were observed in periods when the patient was on a normal diet. Fasting plasma glycerate was $60 \mu \mathrm{mol} /$ liter on two occasions; its concentration was too low to allow a determination of the absolute configuration.

The biochemical effects of the various oral loading tests with L-serine, fructose, and dihydroxyacetone are shown in Figures 1 , 2 , and 3. It is evident that loading with L-serine, which can be thought to be a precursor of D-glycerate via the hydroxypyruvate pathway, had no effect on the excretion of D-glycerate (Fig. 1). Neither hydroxypyruvate nor L-glycerate could be detected after serine loading. Loading with $\mathrm{L}$-serine did not have an effect on plasma glycine; its concentration remained virtually unchanged at values between 357 and $401 \mu \mathrm{mol} /$ liter. Serine showed the expected rise from $139 \mu \mathrm{mol} /$ liter to a peak of $467 \mu \mathrm{mol} / \mathrm{liter}$ after $1 \mathrm{~h}$. Plasma glucose and lactate concentrations during this test were not recorded.

Fructose loading caused a sharp increase in both urinary and plasma glycerate. Urinary glycerate was as high as $68.5 \mathrm{mmol} /$ liter in the first $6 \mathrm{~h}$ after loading (Fig. 1). The duration of the increase of the D-glycerate excretion was rather short; its concentration had already dropped to preloading values in the second 6-h urine sample after loading; neither glyceraldehyde nor hydroxypyruvate could be detected. It could be calculated that only $4.5 \%$ of the fructose intake was recovered as urinary glycerate. Plasma glycerate almost returned to the baseline level after $3 \mathrm{~h}$ (Fig. 2). The disappearance of fructose from the plasma was

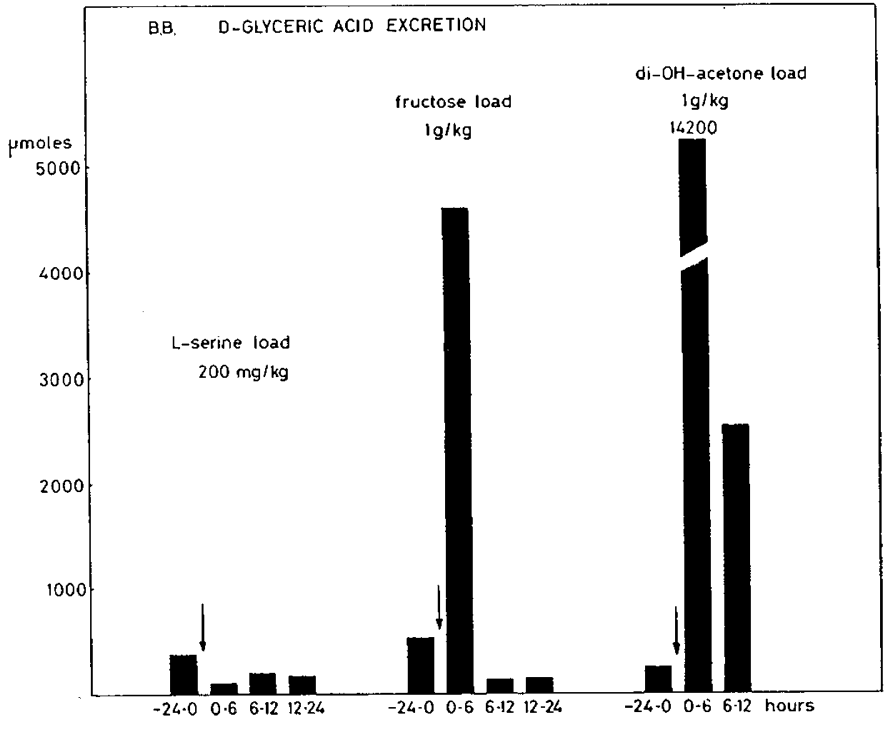

Fig. 1. Urinary excretion of D-glyceric acid in a patient with D-glyceric acidemia during loading tests with L-serine, fructose, and dihydroxyacetone. The start of each loading experiment is indicated with an arrow. Following the dihydroxyacetone load only two urine portions were collected. The amounts of urinary glycerate are expressed as $\mu \mathrm{mol}$ per collection.

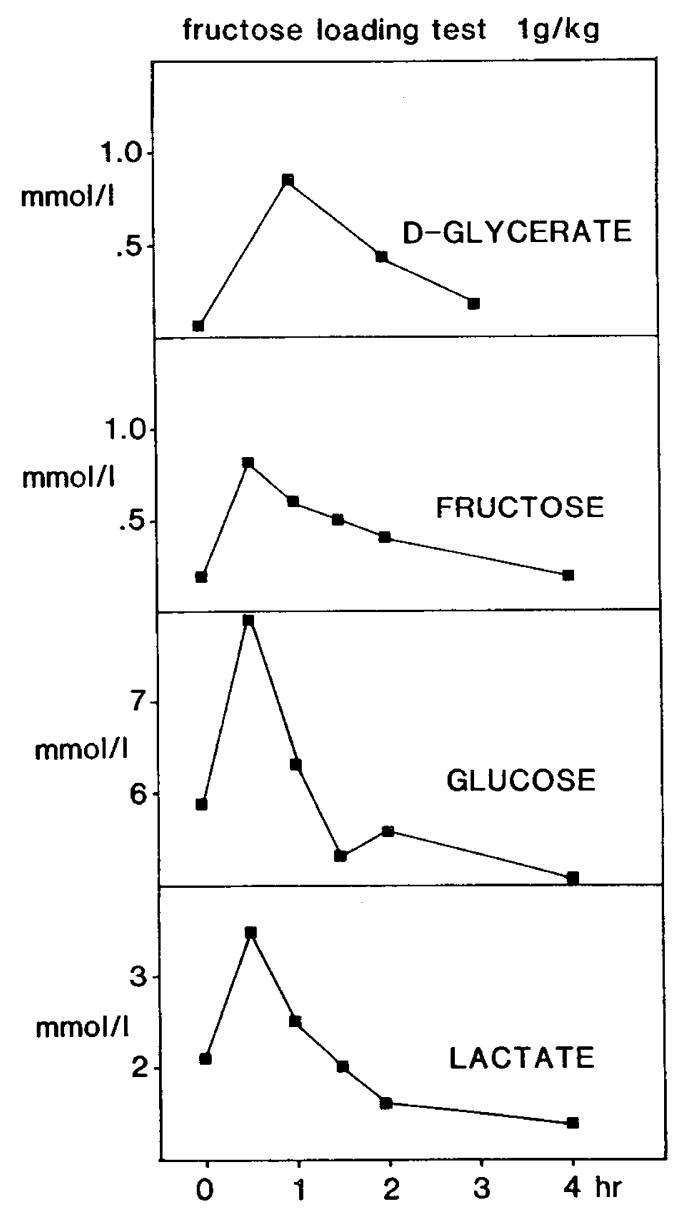

Fig. 2. Results of oral loading with fructose $(1 \mathrm{~g} / \mathrm{kg}$ body weight $)$ in a patient with D-glyceric acidemia. Plasma D-glycerate was measured at hourly intervals. 


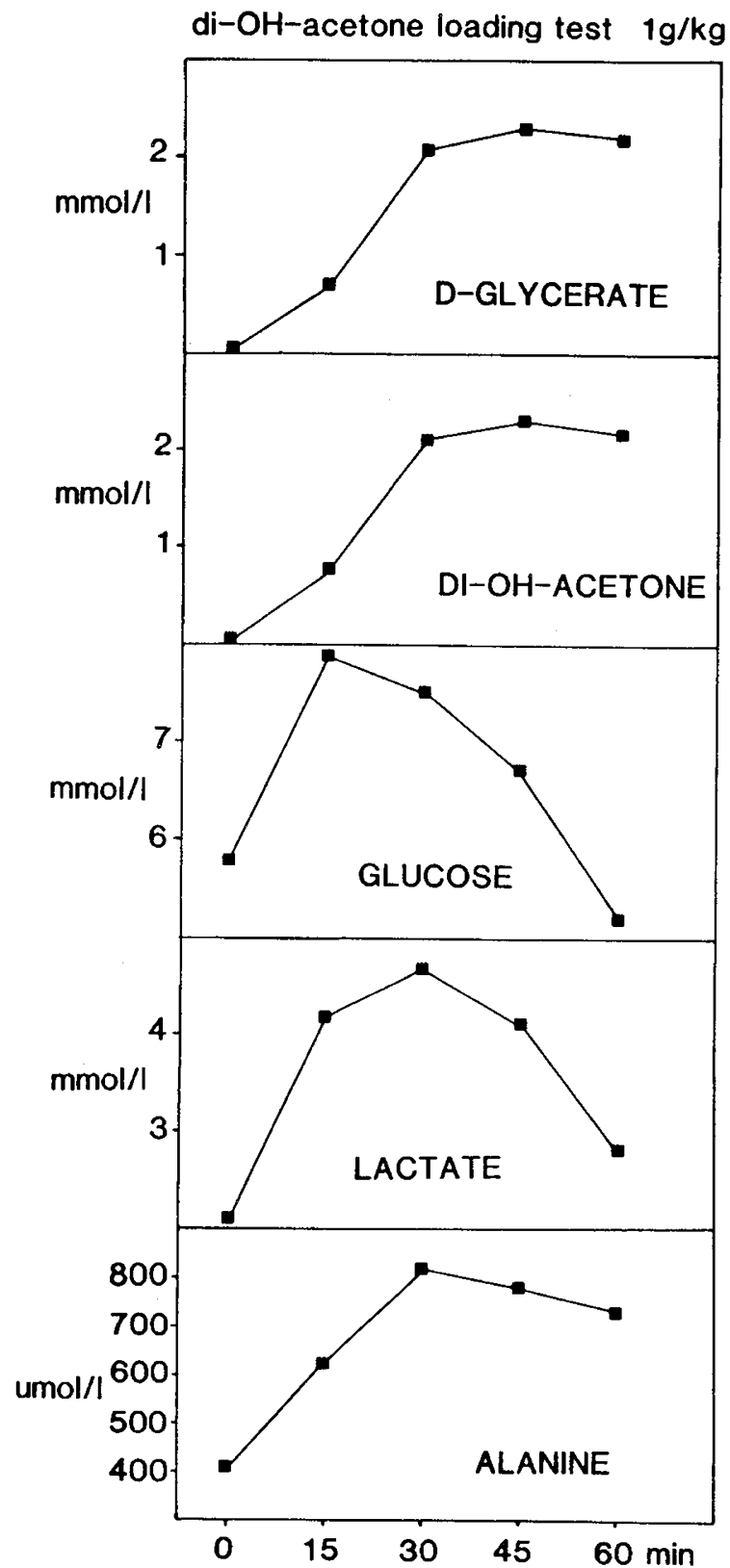

Fig. 3. Results of oral loading with dihydroxyacetone $(1 \mathrm{~g} / \mathrm{kg})$ in a patient with D-glyceric acidemia.

normal: the peak plasma concentration of $0.7-0.9 \mathrm{mmol} / \mathrm{liter}$ at 30-60 min was comparable to that observed in control children after a similar oral load. Plasma glucose and lactate behaved similarly after an initial sharp increase they rapidly fell to preload levels. A healthy adult control who was loaded with $50 \mathrm{~g}$ fructose did not excrete glyceric acid.

The most impressive result was observed after loading with 1 $\mathrm{g} / \mathrm{kg}$ dihydroxyacetone, which led to a peak urinary D-glycerate concentration of $156.9 \mathrm{mmol} /$ liter (Fig. 1). It could be calculated that $16.7 \mathrm{mmol}$ of D-glycerate were excreted in the first $12 \mathrm{~h}$ after the load, representing $8 \%$ of the ingested dihydroxyacetone. During this test plasma glycerate levels were followed for $60 \mathrm{~min}$. As soon as $30 \mathrm{~min}$ after the load a concentration of $2.1 \mathrm{mmol} /$ liter was observed, which did not show a tendency to decrease after $60 \mathrm{~min}$ (Fig. 3). The plasma concentration of dihydroxyacetone paralleled that of D-glycerate, whereas the time course of the concentrations of glucose, lactate, and alanine was different. Plasma serine remained fairly stable during the test; concen- trations between 180 and $240 \mu \mathrm{mol} /$ liter were recorded (graph not shown). Careful analysis of urinary oxo-compounds by gas chromatography/mass spectrometry of the corresponding methoximes or ethoximes revealed some unchanged dihydroxyacetone and a trace of glyceraldehyde in the first urine sample after loading. Hydroxypyruvate was not detected. Loading of a control child with an equivalent amount of dihydroxyacetone led to the excretion of only a trace $(<20 \mu \mathrm{mol} /$ liter) of glyceric acid. None of the loading tests led to adverse clinical reactions in the patient. Following these provocation tests the patient was put on a low fructose/saccharose diet in which fruits were omitted completely and vegetables and potatoes were restricted. She showed some clinical improvement according to the observations of her parents, in particular the frequency of the seizures seemed to decrease somewhat.

Biochemically the effect of the dietary fructose restriction was expressed in a lowering of the D-glycerate excretion; posttreatment urine concentrations of 0.33 and $0.48 \mathrm{mmol} /$ liter were recorded. The assay of the activities of various glycolytic enzymes in erythrocytes showed only one abnormality: GAPD was rather low at $64 \mathrm{U} / \mathrm{g} \mathrm{Hb}$ (controls 142-310). On a separate occasion 69 $\mathrm{U} / \mathrm{g} \mathrm{Hb}$ was found. All other enzymes, including triokinase, showed normal activities. One of the glycolytic intermediates, $v i z$ dihydroxyacetone phosphate, was present in an increased concentration; values of $34 \mathrm{nmol} / \mathrm{ml}$ erythrocytes (fasting) and $91 \mathrm{nmol} / \mathrm{ml}$ erythrocytes (nonfasting) were recorded. The control values are $12.1 \pm 5.1(\mathrm{SD})$.

Enzyme studies in other tissues or cells were not done; one of the reasons was that liver tissue was not available. Neither Dglycerate kinase nor D-glycerate dehydrogenase is expressed in human fibroblasts ( $\mathrm{K} \phi$ lvraa S, personal communication).

Biochemical investigations of the family members did not reveal abnormalities; both the father and the mother excreted no more than trace amounts of glyceric acid. A healthy sister of the patient, born in 1983 and a healthy brother, born in 1985, did not excrete measurable amounts of glycerate.

\section{DISCUSSION}

The present patient adds another one to the hitherto very small series of three D-glyceric acidemia patients. Clinically the patients can be divided into two categories: three with a severe encephalopathy including the present one versus the single patient described by Wadman et al. (2) who exhibited a moderate metabolic acidosis only. Both the Danish patient (1) and the French patient (3) were reported to have the clinical symptoms resembling nonketotic hyperglycinemia. However, these symptoms are rather nonspecific, especially in late onset patients. We therefore prefer not to compare our patient with hyperglycinemia patients. Although valproic acid [= di-(n-propyl) acetic acid] has been shown to interfere with various metabolic processes, we have never experienced abnormal glyceric aciduria due to valproate medication.

Not only is there a clinical difference between the two groups of patients, there also appears to be a biochemical difference. Both the present patient and the Danish patient react to fructose loading (4) by increasing their urinary D-glycerate excretion and Wadman's original patient was the only one to react to a serine challenge (2). Although a defect at the molecular level has not been established in any of the patients, our knowledge about the human metabolism of serine and fructose could be combined with the available data to give a hypothesis.

Although not always unambiguously stated, serine metabolism seems to involve different pathways for synthesis and degradation. It is generally agreed that serine biosynthesis from carbohydrate proceeds via the so-called phosphorylated pathway as shown in Figure 4, reaction sequence 9 (11). Serine catabolism may proceed via three pathways, viz (a) conversion to glycine, (b) formation of pyruvate via D-glycerate (reaction 6 and 7), and (c) direct formation of pyruvate catalyzed by serine dehydratase 




Fig. 4. Scheme showing the interrelation between the metabolism of fructose, glucose, L-serine, and D-glyceric acid. The following steps are indicated: 1 . fructokinase; 2 . aldolase; 3 . triokinase; 4 . glyceraldehyde phosphate dehydrogenase; 5 . aldehyde dehydrogenase; 6 . D-glycerate dehydrogenase; 7. D-glycerate kinase; 8 . triose phosphate isomerase; 9. phosphohydroxypyruvate dehydrogenase; 10 . phosphoserine aminotransferase; 11 . phosphoserine phosphatase; 12 . serine aminotransferase; 13. serine dehydratase. $G-6-P$, glucose-6-phosphate; $F-6-P$, fructose-6phosphate; $F-1-P$, fructose-1-phosphate; $F-1,6-D P$, fructose-1,6-diphosphate; $D H A P$, dihydroxyacetone phosphate; $G A H-3-P$, glyceraldehyde3-phosphate; 1,3-DPG, 1,3 diphosphoglycerate; 3-PG, 3-phosphoglycerate; $2-P G, 2$-phosphoglycerate; $P E P$, phosphoenolpyruvate; 3-P-OH$P Y R, 3$-phosphohydroxypyruvate; 3-P-SER, 3-phosphoserine.

(reaction 13). The latter reaction is of little or no importance in the human (10). Evidence for the catabolism of serine via Dglycerate stems from the existence of patients (11) with L-glyceric aciduria and a partial deficiency of D-glycerate dehydrogenase (enzyme 6), although the flux through this pathway should be small, in view of the low activities of D-glycerate kinase in human as compared to rat liver $(12,13)$. The absence of $\mathrm{L}$-glyceric acid excretion in patients with D-glyceric acidemia provides an indication that their D-glycerate dehydrogenase activity is normal.

The metabolic effects of fructose and dihydroxyacetone in the present patient clearly distinguish her from those with previously discovered disorders of fructose metabolism such as fructosuria, hereditary fructose intolerance, and fructose-1,6-diphosphatase deficiency (14). Nevertheless this patient is likely to suffer from a defect in the intermediary metabolism of fructose. The normal metabolism of fructose proceeds via fructose-1-phosphate to glyceraldehyde and dihydroxyacetone phosphate (Fig. 4). Glyceraldehyde can be metabolized as follows: (a) reduction to glycerol (not shown in Fig. 4), (b) oxidation to D-glycerate catalyzed by aldehyde dehydrogenase (reaction 5), and (c) phosphorylation catalyzed by triokinase (reaction 3 ). It is generally agreed that the latter reaction is favored in human liver $(15,16)$, followed by oxidation of the reaction product glyceraldehyde-3phosphate to 3-phosphoglycerate. Thereafter our results from the fructose loading are not incompatible with a partial deficiency of triokinase or a $\mathrm{K}_{\mathrm{M}}$-variant of this enzyme. A deficiency of triokinase would promote the conversion of glyceraldehyde to D-glycerate. As this D-glycerate apparently could not sufficiently be metabolized further, the logical conclusion would be that the capacity to metabolize D-glycerate with D-glycerate kinase was surpassed. This implies that liver and erythrocyte are different enzymes, the activity of the latter being entirely normal in the present patient. An enzyme anomaly even lower in the fructose catabolic pathway is considered to be less likely, as this pathway is shared by fructose and glucose, and the continuous high glucose turnover would lead to much higher D-glycerate excretions if this were the case.
Dihydroxyacetone has to be very close to the primary defect as judged by the result of the loading test. Its metabolic fate is phosphorylation by triokinase or by glycerol kinase to dihydroxyacetone phosphate, the latter enzyme has a much higher $\mathrm{K}_{\mathrm{M}}$ for dihydroxyacetone (17). The phosphorylated product is then isomerized to glyceraldehyde-3-phosphate (Fig. 4, reaction 8). Malfunctioning of triokinase will lead to accumulation of the ingested dihydroxyacetone which could possibly be converted to D-glycerate by a sequence of reactions: (i) oxidation to hydroxypyruvaldehyde by alcohol dehydrogenase followed by (ii) oxidation to hydroxypyruvate by aldehyde dehydrogenase and (iii) conversion to D-glycerate by D-glycerate dehydrogenase (Fig. 4, reaction 6). The limited capacity of the liver to phosphorylate D-glycerate would then cause an excessive D-glyceric aciduria. The enzyme defect in this patient (presumably triokinase) has to be partial because only a small portion of the loads was excreted in the form of D-glycerate.

To the best of our knowledge a deficiency of triokinase has not been described before, hence it is not known if such a deficiency could result in a distinct clinical picture.

Our patient did not excrete abnormal amounts of short-chain acylglycines as was described in the Danish patient (18). In our opinion there is no relation between the abnormality leading to D-glyceric aciduria and the inability to metabolize short-chain fatty acids.

Although D-glyceric aciduria seems to be extremely rare (this patient is only the fourth one reported) the assumption can be made that more patients can be found. We have shown that there may be a considerable variation of the daily D-glycerate output and it can thus be advocated to perform provocative loading tests with fructose and dihydroxyacetone in patients who excrete only small amounts of glyceric acid.

Acknowledgments. The authors thank Dr. J. P. Kamerling, Department of Bio-organic Chemistry, State University Utrecht, for the synthesis of D- and L-glyceric acid; Dr. S. Kølvraa, Department of Human Genetics, University of Aarhus, for his helpful discussions; Prof. Dr. G. E. J. Staal and Dr. G. Rijksen, Department of Medical Enzymology, University Hospital Utrecht, for their measurement of intermediates/enzyme activities of glycolysis, and Dr. N. A. Pikaar and coworkers (CIVO/ TNO) for the fructose determinations.

\section{REFERENCES}

1. Brandt NJ, Rasmussen K, K $\phi$ lvraa S, Schonheyde F 1976 D-Glyceric acidaemia and non-ketotic hyperglycinaemia. Clinical and laboratory findings in a new syndrome. Acta Paediatr Scand 65:17-22

2. Wadman SK, Duran M, Ketting D, Bruinvis L, de Bree PK, Kamerling JP, Gerwig GJ, Vliegenthart JFG, Przyrembel H, Becker K, Bremer HJ 1976 DGlyceric acidemia in a patient with chronic metabolic acidosis. Clin Chim Acta 71:477-484

3. Grandgeorge D, Favier A, Bost M, Frappat P, Boujet C, Garrel S, Stoebner P 1980 L'acidémie D-glycérique. A propos d'une nouvelle observation anatomo-clinique. Arch Fr Pediatr 37:577-584

4. Kфlvraa S, Rasmussen K, Brandt NJ 1976 D-glyceric acidemia: biochemical studies of a new syndrome. Pediatr Res 10:825-830

5. Duran M, Ketting D, van Vossen R, Beckeringh TE, Dorland L, Bruinvis L, Wadman SK 1985 Octanoylglucuronide excretion in patients with a defective oxidation of medium-chain fatty acids. Clin Chim Acta 152:253-260

6. Wohl A, Schellenberg R 1922 Die Überführung des aktiven Glycerinaldehyds in die aktive Glycerinsäure. Chem Ber 55:1404-1408

7. Beutler E 1975 Red Cell Metabolism; A Manual of Biochemical Methods, 2nd ed. Grune and Stratton Inc, New York, pp 38-70

8. Zender R, Falbriard A 1966 Analyse colorimétrique des céto-hexoses et de l'inuline par la réaction à l'acide thiobarbiturique. Clin Chim Acta 13:246250

9. Kфlvraa S, Gregersen N, Christensen E 1984 In vivo studies on the metabolic derangement in a patient with D-glyceric acidaemia and hyperglycinaemia. J Inherited Metab Dis 7:49-52

10. Snell K 1986 The duality of pathways for serine biosynthesis is a fallacy. Trends Biochem Sci 11:241-243

11. Chalmers RA, Tracey BM, Mistry J, Griffiths KD, Green A, Winterborn MH 1984 L-Glyceric aciduria (primary hyperoxaluria type 2) in siblings in two 
unrelated families. J Inherited Metab Dis 7(suppl 2):133-134

12. Heinz F, Lamprecht $W$, Kirsch $J 1968$ Enzymes of fructose metabolism in human liver. J Clin Invest 47:1826-1832

13. Kitagawa $\mathrm{Y}$, Katayama $\mathrm{H}$, Sugimoto $\mathrm{E} 1979$ Identity of mitochondrial and cytosolic glycerate kinase in rat liver and regulation of their intracellular localization by dietary protein. Biochim Biophys Acta 582:260-275

14. Baerlocher K, Gitzelmann R, Steinmann B 1980 Clinical and genetic studies of disorders in fructose metabolism. In: Burman D, Holton JB, Pennock CA (eds) Inherited Disorders of Carbohydrate Metabolism. MTP Press Ltd, Lancaster, pp 163-190

15. Sillera MAG, Sillero A, Sols A 1969 Enzymes involved in fructose metabolism in liver and the glyceraldehyde metabolic crossroads. Eur J Biochem 10:345-
350

16. Hue $\mathrm{L}$, Hers $\mathrm{HG} 1972$ The conversion of $\left[4{ }^{3} \mathrm{H}\right]$ fructose and of $\left[4-{ }^{3} \mathrm{H}\right]$ glucose to liver glycogen in the mouse. An investigation of the glyceraldehyde crossroads. Eur J Biochem 29:268-275

17. Beutler E, Guinto E 1973 Dihydroxyacetone metabolism by human erythrocytes: demonstration of triokinase activity and its characterization. Blood 41:559-568

4. Kфlvraa S, Rasmussen K, Brandt NJ 1976 D-glyceric acidemia: biochemical studies of a new syndrome. Pediatr Res 10:825-830

18. Kфlvraa S, Gregersen N, Brandt NJ 1980 Excretion of short-chain N-acylglycines in the urine of a patient with D-glyceric acidemia. Clin Chim Acta $106: 215-221$ 